\title{
Percepções de bolsistas ProUni acerca do pertencimento ao ensino superior privado
}

\author{
Ruy de Deus e Mello Neto \\ Universidade de São Paulo \\ Hugo Augusto Vasconcelos Medeiros \\ Universidade Federal de Pernambuco \\ Afrânio Mendes Catani \\ Universidade de São Paulo
}

\section{Resumo}

0 objetivo deste artigo é discutir a construção da identidade social dos estudantes bolsistas integrais do Programa Universidade para Todos (ProUni) em relação ao seu pertencimento à educação superior e à faculdade privada, tomando por base a ideia de "ruptura" em sua identidade social a partir do contato com uma nova fronteira social. Para tanto, realizamos análise de entrevistas semiestruturadas com bolsistas integrais ProUni no Estado de Pernambuco, mediada pelas teorias do capital cultural e do habitus, de fronteira simbólica e de configuração estabelecidos-outsiders. Esperamos contribuir para um melhor entendimento do impacto causado pela possibilidade de cursar a educação superior na construção da identidade destes estudantes.

Palavras-chave: Educação superior. ProUni. Pertencimento. Habitus. 


\section{ProUni Fellow's perceptions about belongingness to private higher education}

The aim of this paper is to discuss the construction of ProUni fellows' social identity in terms of their belongingness to Higher Education and to private schools, based on the idea that there is a "rupture" in their social identity from the point when they encounter a new social border. To that end, we have analyzed semi-structured interviews with ProUni fellows in the State of Pernambuco, mediated by the concepts of cultural capital and habitus, symbolic border, and established/outsiders configurations. We expect to contribute to a better understanding of the impact of the possibility of undergoing undergraduate studies on the building of these students' identities.

Keywords: Higher Education. ProUni. Belongingness. Habitus.

\section{La percepción de los becarios del ProUni acerca de la pertenencia a la educación superior privada}

El objetivo de este trabajo es discutir la construcción de la identidad social de los becarios del ProUni en relación a la pertenencia a la Educación Superior y Privada, teniendo como base que hay una "ruptura" en su identidad social, ya que tiene el contacto con una nueva frontera social. Para ello, a través de los conceptos de capital cultural y habitus, frontera simbólica, y las configuraciones establecidos-outsiders, hemos analizado las entrevistas semiestructuradas de los becarios ProUni en Pernambuco, donde esperamos contribuir con la comprensión del papel que las vivencias en la graduación de facultades privadas tienen en la construcción de las identidades de estos estudiantes.

Palabras-clave: Educación superior. ProUni. Pertenencia. Habitus. 


\section{Introdução}

A literatura internacional destaca um grande gap de acesso e de desempenho escolar entre as diferentes classes sociais. Este é potencializado no sistema de ensino superior, especialmente em instituições de prestígio (Zimdars, 2010; Ayalon et al., 2008), devido a políticas sociais e econômicas que alimentaram as desigualdades encontradas na educação superior. (Gross; Cheng, 2011)

Entretanto, historicamente, as causas sociais tendem a ser colocadas de lado, em nome da qualidade da educação (Alon; Tienda, 2007; Lamont; Silva, 2009). Há, principalmente entre as instituições de prestígio, um discurso conservador e meritocrático, permeado pela ideia de que estas instituições destinam-se aos melhores estudantes e de que o problema do processo seletivo não está na Instituição de Ensino Superior (IES), mas na má qualidade da formação dos estudantes de baixa renda, PPI, ${ }^{1}$ e da escola pública nos níveis mais básicos de educação (McCowan, 2007). Historicamente, as ações afirmativas governamentais têm visado à correção das desvantagens oriundas de históricos sociais específicos (Warikoo; Carter, 2009; Lareau, 1987), deixando de lado questões estruturais.

No caso brasileiro, com respaldo legal do inciso V do art. $4^{\circ}$ da LDB, as instituições de maior prestígio têm sido relutantes em relação a adotar políticas de ingresso baseadas em critérios raciais e de renda (Tavolaro, 2008). Contrariamente, postula-se há décadas como requerimento básico ao desenvolvimento nacional a ampliação do número de estudantes na educação superior (Carvalho, 2006). Desde - Plano Nacional de Educação² (PNE 2001-2010), admite-se a necessidade de expansão do número de vagas ocupadas na educação superior para jovens entre 18 e 24 anos, especialmente para os de baixa renda e com históricos familiares de desvantagem social.

O ProUni (2005) - Programa que amplia o acesso à educação superior a grupos historicamente dela afastados (Oliven, 2012) por meio da oferta de bolsas a estudantes de baixa renda em Instituições Privadas de Ensino Superior (Ipes) brasileiras (Sisprouni, 2014) -, tem sido utilizado pelo governo como uma política pública central para o aumento das matrículas sem, contudo, colocar em pauta a ampliação do acesso ${ }^{3}$ a instituições públicas de excelência.

Sob o efeito de programas como este, a educação superior vivencia modificações em parte do perfil do corpo estudantil. Encaminhado para o acesso massificado,

\section{Pretos, Pardos e Indígenas.}

2. BRASIL. Presidência da República. Lei no 10.172, de 9 de Janeiro de 2001.

3. Ainda há relutância em adotar leis semelhantes à Lei n 12.711/2012 (Lei de cotas nas instituições federais) em grande parte das universidades estaduais do País. Dentre elas, as universidades do Estado de São Paulo, reconhecidas como de referência no País. 
abre a possibilidade para que o estudante pobre, negro, de escola pública, antes convencido de que a educação superior não the pertencia, possa perceber este nível de ensino como oportunidade de ascensão social (Francis; Tannuri-pianto, 2012b; Schwartzman; Silva, 2012). Esta possibilidade, até então inédita, de ampliar o poder disponível (e necessário) ao sucesso das suas trajetórias em um ambiente de distribuição social desigual (Bourdieu, 1998b) faz com que a expectativa de êxito impacte diretamente nas estratégias escolares dos estudantes.

Contudo, as possibilidades de êxito e de alteração da trajetória pelo ProUni são restritas, pelos seguintes motivos: a oferta de vagas dá-se, sobretudo, em instituições de segundo escalão - o que é uma estratégia de Estado comum na garantia do acesso universal (Catani; Gilioli, 2005; Bourdieu, 2008) -; e a vaga garante somente (e no máximo) o primeiro passo - a diplomação. Se somarmos a isto o fato de os estudantes serem selecionados com um crivo consideravelmente maior que seus colegas não bolsistas ${ }^{4}$, perceberemos que thes é ofertada, a um alto custo, a oportunidade de serem melhores estudantes em instituições de segundo escalão. (Mello Neto, 2014)

Podemos dizer que estes estudantes são expostos a um ambiente em que se configuram relações sociais extremamente distintas das suas; e no qual se inserem, também, a partir de configurações outras: diante de processos seletivos normalmente mais rigorosos do que os tradicionais em IES privadas, vão ser estudantes bem ranqueados em uma faculdade particular, onde a maioria dos outros estudantes tende a vir de escolas particulares, famílias de renda mais elevada e mesmo de outra raça. Assim, como os bolsistas acessam a educação superior com "desvantagens" sociais, mas com vantagens de desempenho escolar, tende a criar-se uma identidade social e um pertencimento distintos, tanto da sua família quanto dos outros estudantes. Deste modo, sua identidade e pertencimento social, produzidos por meio da família e da escola anterior, são rompidos, sem que eles possuam capital cultural suficiente para se integrarem prontamente ao grupo de alunos da instituição em que estudarão.

Nosso objetivo neste artigo é analisar a construção da identidade social e do pertencimento social pelos bolsistas integrais ProUni. Parte-se da premissa segundo a qual tais estudantes, dotados de um volume de capital social distinto do de seus futuros colegas, pontuado por um capital escolar mais elevado e por um capital cultural geral mais baixo, ao ingressarem em IES privadas, encontramse numa situação única de ruptura com suas categorias e elementos identitários tradicionais, impossibilitados que se encontram de substituí-los, imediatamente,

4. Naquele ano, em Pernambuco (Inep.Superior, 2012), a relação candidato/vaga média em IES privadas no Estado foi de 1,33, enquanto a concorrência estadual estipulada para ProUni foi em média de 19,15 candidatos por vaga. 
pelos novos encontrados em seu horizonte. Para construir nossa análise, partiremos da noção de capital cultural, desenvolvida por Pierre Bourdieu, e da de fronteira simbólica, de Michèle Lamont, além de diversas contribuições da sociologia a respeito da identidade social. Como dados primários, utilizaremos entrevistas semiestruturadas, realizadas entre outubro de 2013 e fevereiro de 2014, com egressos bolsistas de IES privadas no Estado de Pernambuco entre os anos de 2010 e 2014.

\section{A construção da identidade e do pertencimento social em situações de mobilidade social}

Para Bourdieu (1998a), o acesso à educação superior é resultado de uma seleção direta ou indireta que, ao longo da escolarização, pesa com rigor desigual para sujeitos de diferentes classes sociais, de acordo com a desigual distribuição do capital cultural (Bourdieu, 1979). Como não há a necessária correlação entre o acesso à educação formal e o acúmulo de capital cultural, a igualdade formal esconde uma desigualdade real (Bourdieu, 1998a), com a escola exercendo papel central na continuidade desta relação ao atribuir esperanças de sucesso escolar a todos os jovens e escamotear os papéis da hierarquia social, da distribuição do capital cultural, do processo seletivo e da certificação para o sucesso escolar. (Bourdieu, 2007)

A posição social inicial e o capital de origem não são o bastante para determinar a trajetória dos membros de uma classe, a qual, pelo menos para alguns subconjuntos, tende a desviar-se verticalmente, aproximando-se do padrão de outra classe (Bourdieu, 2007). A análise deve levar em conta não só a posição relativa, mas a própria curva sobre a qual se desenha a trajetória (Bourdieu, 1974), implicando que a mesma posição pode carregar diferentes significados, de acordo com a trajetória específica.

Em busca das melhores trajetórias, as diferentes classes e frações de classes permanecem em constante disputa simbólica para impor sua visão e perpetuarem, no âmbito cultural, a sua posição social (Bourdieu, 1989). Os sistemas simbólicos, além de cumprirem a função política de legitimação da dominação ("violência simbólica"), permitem produzir "efeitos reais sem dispêndio aparente de energia" (Bourdieu, 1989, p. 15). 0 domínio dos sistemas simbólicos é em si disputado, já que a classe dominante hierarquiza-se de acordo com as frações dominantes, detentoras de maior capital econômico que, na construção do processo de hierarquização, dão precedência a seus motivos e aspirações, servindo aos “interesses dos dominantes [somente] por acréscimo". (Bourdieu, 1989, p. 12) 
Assim, o ProUni, mesmo buscando subverter uma lógica de igualdade formal entre jovens, alimenta o processo de manutenção da desigualdade. Desde o processo de seleção, colocam-se em pé de igualdade jovens considerados como igualmente desprovidos de capital econômico, originários das mais diferentes matrizes familiares, desconsiderando-se as distintas trajetórias escolares, acúmulo de capital ${ }^{5}$ (de todos os tipos) e diferentes habitus ${ }^{6}$ de cada grupo. Em adição, segundo os microdados do Exame Nacional do Ensino Médio - ENEM 2012 -, mais de $75 \%$ dos jovens inscritos no exame no Estado de Pernambuco estariam aptos a concorrer a uma bolsa integral.

Assim, podemos dizer que, embora a escolha dos candidatos dê-se segundo recorte específico, tendo por objetivo criar um público-alvo que efetivamente necessite e se beneficie da política, atuando, portanto, na materialidade do problema, tendo em vista reparar uma desigualdade histórica persistente la qual, dificilmente, mudaria "espontaneamente" sem a política); a escolha final dos candidatos, devido a sua centralidade no aspecto meritocrático, preocupa-se mais com o âmbito formal (de criar critérios rígidos e "justos" para a seleção), tornando-se, na prática, restritiva (visto que reduz o impacto sobre o público alvo) e conservadora, uma vez que não permite uma ampla modificação do quadro de desigualdade persistente, já que os candidatos terminam por se deparar com uma seleção muito mais rigorosa do que a enfrentada por seus futuros colegas. Em resumo, como o acesso ao benefício é deslocado para a nota de ingresso (meritocracia), temos dois sistemas antagônicos dentro do Programa: material e reparatório na definição dos beneficiários versus formal e conservador na seleção final dos candidatos.

Estes antagonismos levam os candidatos a situação peculiar, a qual tende a provocar uma ruptura em sua trajetória de identificação social: embora tenham a aparência de "excluídos incluídos", suas notas maiores e sua seleção mais rígida colocam-nos, pelo menos no que toca o capital escolar, como mais aptos ao sucesso no curso do que seus colegas não bolsistas. (Mello Neto, 2014)

Mesmo sendo tentador acompanhar o recorte do ProUni e observar os estudantes unicamente pelo recorte de classe, uma análise mais detida mostra que tal clivagem não é suficiente para explicar em definitivo as diferenças culturais e de identificação como um todo (Lamont; Lareau, 1988; Modood, 2004; Hall, 2005). Nesse sentido, ganham relevo as ideias de que grupos específicos se posicionam

5. O ProUni adota como critério de elegibilidade a renda per capita máxima de 1.5 salários mínimos para bolsa integral e 3 salários mínimos para bolsa parcial. 0 estudante deve ter cursado todo o ensino médio em instituição pública ou em instituição privada com bolsa.

6. Sistema de disposições duráveis e transponíveis que, integrando todas as experiências passadas, funciona a cada momento como uma matriz de percepções, apreciações e ações. (Bourdieu, 2002, p.167) 
e operacionalizam suas decisões e trajetórias de acordo com as possibilidades de sucesso do grupo (Almeida et al., 2010), não havendo correspondência exata entre "trajetórias objetivas" e formas identitárias (Dubar, 1998), de modo que trajetórias descendentes podem implicar identidades conservativas, por exemplo.

É necessário, para esta análise, complementar a teoria do capital cultural com abordagens que privilegiem outras clivagens e permitam melhor perceber as mudanças atuais na identidade social e no pertencimento social, tomando como ponto de partida a ideia de compreensão dinâmica e histórica das diferenças sociais.

Optamos pela ideia de "fronteiras simbólicas" (Lamont; Mólnar, 2002), entendidas como estruturas objetivadas de diferenciação entre pessoas que se identificam como pertencentes a um grupo específico, o qual se identifica e se organiza em torno de uma unidade de autorreconhecimento e de pertencimento. As fronteiras simbólicas constituem-se de um sistema de hierarquização entre grupos, visando à definição da semelhança entre os indivíduos pertencentes a um grupo de acordo, inclusive, com parâmetros morais. Trata-se de distinções traçadas entre objetos, pessoas e práticas; distinções que operam como um sistema de regras que serve de guia da interação entre pessoas e seus atos sociais. Assim, num cenário em que o reconhecimento geral é objetivamente desigual, com acesso diferenciado e a distinta distribuição de capital (material e imaterial), a fronteira delimita características (ou capitais) que dão significado ao grupo. (Lamont; Fournier, 1992; Small; Harding; Lamont, 2010)

Em leitura a partir da perspectiva da fronteira simbólica, Moon (2012) sugere que, quando membros de um grupo estigmatizado veem nas narrativas dominantes algo inalcançável - ao ponto de a tentativa se tornar autodestrutiva -, há uma tendência desses indivíduos a responderem a tal fato se definindo e defendendose explicitamente: criam barreiras que os isolam em definitivo do grupo dominante e significam sua existência nos membros do próprio grupo. Adicionalmente, eles produzem um modelo de individualidade coletiva definida como embattled selfhood (individualidade aguerrida), em que os atores engajados na reificação das suas identidades específicas criam uma espécie de senso de segurança baseada na diferença entre o "nós" e o "eles" - diferença esta fixada na eterna oposição "nós somos vitoriosos", "eles são maus", “nós somos oprimidos”, “eles são opressores" etc.

Além disso, havemos de considerar o atual momento histórico, em que a identidade e o pertencimento social são (re)formulados e (trans)formados de maneira fluida, não mais correspondendo, portanto, à ideia de autoidentificação e de continuidade, do ser consigo ao longo do tempo. Ao sermos bombardeados por um considerável feixe de sistemas culturais, não escolhemos mais nossas 
identidades de forma estática, automática ou monolítica, mas de acordo com prevalências e preferências, segundo diferentes práticas e expectativas. (Castells, 1999; Dubar, 2011; Hall, 2005; Laclau, 1992; Santos, 2002)

Neste cenário, em que a globalização e as mudanças tanto na sociedade quanto na sociologia em si apontam para uma crise nas categorias tradicionais de identificação, Castells (1999) afirma a existência de "identidades de resistência", as quais são formadas por atores em posições sociais desfavoráveis, com base em princípios diferentes daqueles dos grupos e instituições sociais dominantes, de forma a resistir e a sobreviver diante da tendência de expansão da "identidade legitimadora" la qual se liga aos grupos e instituições dominantes, a seus princípios e hierarquia social).

Entre os estudos voltados ao acesso dos jovens com baixo capital econômico à educação superior, é comum assumir que a origem social do estudante tornase responsável por muitos dos aspectos ruins que afetam as experiências e interações sociais ocorridas nas instituições, podendo trazer consequências maléficas ao seu desempenho escolar. Ostrove (2003) sugere que estudantes com origens socioeconômicas desfavoráveis tendem a se sentir ainda mais marginalizados durante os anos de educação superior, uma vez que o senso de pertencimento do próprio estudante tem relação diretamente proporcional com as experiências, o desempenho e a evasão escolar (Ostrove; Long, 2007; Goldrickrab, 2006; Lehmann, 2007). Por fim, deve-se registrar que o pertencimento toca a adaptação do jovem à escola que, por sua vez, passa pela imposição da aquisição de perspectiva cultural dominante, forçando que se deixe de lado a bagagem cultural trazida pelo estudante não dominante. (Bergerson, 2007)

Aries e Seider (2005), a partir de comparação das trajetórias de estudantes de baixa renda em diferentes instituições norte-americanas, demonstram que a influência do capital cultural é relativa, pois o contexto social das instituições influencia diretamente a experiência dos estudantes. Nesse sentido, os estudantes de baixa renda tendem a se sentir mais adaptados em instituições de segundo escalão, devido não à menor desigualdade de capital e, sim, à maior diversidade presente em tais instituições.

Com isso podemos resumir que, embora o capital cultural influencie a identificação e o pertencimento dos estudantes em situação de mobilidade social, ele não é definitivo, já que elementos culturais e institucionais desempenham elevado peso na categorização e na trajetória dos indivíduos. No caso dos bolsistas ProUni, estes se encontram emparedados entre um duplo deslocamento da trajetória familiar pregressa e o novo padrão de trajetória, acentuado pela contradição de possuírem menor capital cultural, mas melhor desempenho escolar que seus colegas. 0 rearranjo levou-os à criação de duas falas: uma 
depreciativa (pautada pela ausência de mérito) em relação a seus colegas não bolsistas, e outra, elogiosa, para seu próprio grupo - o qual, na verdade, começara a existir junto com o próprio Programa -, a partir da eleição, arbitrária, de valores de distinção. (Elias; Scotson, 2000)

\section{Metodologia e limites do estudo.}

Este trabalho ocupa-se do jovem recém-formado que foi bolsista do ProUni, o que, por si só, já caracteriza um recorte de sujeito específico pré-definido. 0 indivíduo foi classificado ${ }^{7}$ em uma faixa de renda pré-estabelecida e concluiu o ensino médio na rede pública de ensino ou foi bolsista da rede privada. Assim, a única exigência de seleção para esta pesquisa foi que ele tenha sido bolsista do ProUni Integral ${ }^{8}$ e concluído sua graduação nesta situação.

Dada a precária qualidade dos bancos de dados das IES brasileiras - em especial no que se refere a alunos egressos -, a identificação passou necessariamente pelo acesso a indivíduos que foram entrevistados em pesquisa anterior (Mello Neto, 2011). Assim, o ponto inicial do trabalho foi entrar em contato com pessoas que estivessem no estágio final de conclusão das suas graduações no período de realização da pesquisa anterior, correspondendo ao segundo semestre de 2010.

A partir da identificação e do aceite de participação dos indivíduos que já haviam respondido a questionários em 2010, foi adotada como metodologia a Snowball Sampling. Essa decisão passou pela caracterização da pesquisa em si, uma vez que tal metodologia é indicada para populações cujo acesso é dificultado?.

A decisão pela metodologia de amostragem Snowball sampling, explicada em detalhes a seguir, trouxe consigo a limitação no número de instituições nas quais foram entrevistados estudantes. Assim, a coleta de dados concentrou-se em seis IES pernambucanas: Universidade Católica de Pernambuco, Centro Universitário Maurício de Nassau, Faculdade Joaquim Nabuco, Faculdade Vale do Ipojuca, Faculdades Integradas Barros Mello e Faculdade Integrada de Pernambuco.

O Censo da Educação Superior 2012 (Inep. Superior, 2013) mostra que o grupo de

7. Não será considerada a renda atual e, sim, o fato de ter sido bolsista, enquadrando-o pela renda no momento em que entrou no ensino superior. De outra forma, excluiríamos estudantes egressos que tiveram aumento de rendimento decorrente da diplomação.

8. Uma vez que a intenção do trabalho é perceber as diferenças em decorrência do acesso e da vivência no ensino superior, inédito em famílias de baixa renda, resolvemos, em função do menor limite de renda permitida, observar apenas bolsistas integrais.

9. Bernard (2006) aponta três caracterizações de uma população considerada como de difícil acesso: (1) poucos membros em um universo grande; (2) populações estigmatizadas ou reclusas; ou (3) membros de um grupo de elite que não têm interesse em contribuir com a pesquisa. 
bolsistas integral do ProUni representa apenas 2,6\% dos estudantes matriculados na educação superior no Estado de Pernambuco. Ainda que se observassem apenas os estudantes da rede privada, os bolsistas integrais do ProUni representam apenas $4,3 \%$ dos estudantes pernambucanos na educação superior, o que evidencia a dificuldade de identificação ou de seleção de amostragem aleatória.

Além disso, os estudantes tendem a resistir em participar do estudo e em colaborar, enquanto as IES dificultam o acesso institucional a estes alunos (Mello Neto, 2011; Almeida, 2012). Desta forma, se torna improvável um estudo focando estudantes (e egressos) bolsistas integrais do ProUni sem que se identifique ao menos um pequeno grupo deles inicialmente.

A metodologia do Snowball Sampling faz crer que, em universos restritos, é possível a identificação de uma amostra que possa explicá-lo. Contrária a ela pesa o fato de ser uma metodologia incapaz de explicar situações para além do espaço amostral, sendo passível a criação de viés no caso de tentativas (Goodman, 1961). Entretanto, mostra-se bastante competente quando se considera uma população específica ou quando é possível desconsiderar o universo total - estudos de caso ou estudos de caso-controle, por exemplo. (Dragan; Isaic-Maniu, 2013; Lopes; Rodrigues; Sichieri, 1996)

A partir do processo de indicação de novos participantes por meio dos inicialmente selecionados, e assim sucessivamente, levam-se em conta as interações entre os sujeitos entrevistados. Ou seja, interessa saber, além das perspectivas próprias do sujeito, a forma com a qual ele identifica seus pares. Em seguida, há a solicitação de dados sobre sujeitos a serem indicados e, a partir deste instante, vai-se a campo para recrutá-los. Este processo de indicação deve ser mantido até que o pesquisador perceba que o ponto de saturação da pesquisa foi encontrado: os novos indivíduos passaram a não interferir no padrão de resposta obtido ou passaram a indicar somente sujeitos que já tenham participado do estudo. No caso deste trabalho, o padrão encontrado nas respostas nos fez crer que teríamos um ponto de saturação.

\section{Vivências e pertencimento à educação superior para a primeira geração das famílias com acesso a este nível de ensino.}

Para analisar a situação que descrevemos até aqui, entrevistamos 22 indivíduos que concluíram a graduação sob o financiamento integral do ProUni, questionandoos sobre suas experiências e vivências na educação superior ${ }^{10}$. Ao fim desta

10. 20 deles egressos de IPES de alto custo, ocupadas majoritariamente por grupos sociais distintos do perfil dos bolsistas ProUni. Destas, 6 tinham mensalidades 1,8 vezes maior e 14 tinham mensalidades 2 vezes maior que o limite, no período, da renda máxima permitida para bolsistas. 
fase do estudo, foram estruturadas duas categorias analíticas: (a) percepção dos estudantes sobre as diferenças sociais e econômicas entre bolsistas e não bolsistas; e (b) percepção dos bolsistas sobre seu desempenho escolar e sobre o desempenho escolar dos não bolsistas. Restou confirmada a premissa inicial: há um choque cultural em relação aos novos e antigos estudantes que, devido à desigualdade socioeconômica e cultural, exige, sobretudo dos primeiros, uma reidentificação - como expressa o relato abaixo:

Eu trazia meu lanche de casa, por exemplo. Isto sempre assustou meus colegas mais ricos. Eles me olhavam como alguém que fazia alguma coisa errada. No começo da faculdade, eu não tinha roupas legais como eles tinham. Imagina você vendo suas colegas cheias de roupas legais e você não (pausa) isso era ruim, eu não gostava, mas (pausa) o que eu poderia fazer? Eu tinha roupas simples e precisava usar elas. Só comprei coisas melhores para mim quando consegui trabalho no fim do curso, daí comecei a ganhar algum dinheiro. Algumas vezes eu ouvi coisas ruins sobre isso, por exemplo, quando me diziam que não me chamavam para sair porque eu não tinha dinheiro para ir para os lugares que eles iam. Eu ficava chateada, queria era conversar com as pessoas, não ligava de chegar lá e tomar uma coca-cola. Se era o que eu poderia pagar, eu não ligava, não. Muitos deles se sentiam incomodados de sair comigo para me ver tomando uma coca-cola. Eles não gostavam disto. Muitas vezes sei que não fui convidada para festas da turma por isto. Eles não me chamavam porque achavam que eu não poderia ir. (pausa) Pra dizer a verdade, normalmente eu ignorava a preocupação e ia assim mesmo. (T, 25 anos)

A fala de T. mostra o quão difícil pode ser o processo de adaptação. Há uma marcação evidente das diferenças entre T. e seus colegas, e entre a T. de início de curso e a T. de fim de curso (após conseguir um trabalhol. Nota-se que T. buscava lutar contra a exclusão a que se sentia submetida. Tal qual exposto por Elias e Scotson (2000), a diferenciação dos grupos sociais não toca - ou, pelo menos, não da mesma forma - todos os espaços sociais: os estudantes bolsistas convivem com os não bolsistas na faculdade, mas, diante da diferença de acesso a bens materiais e culturais, sentem resistência para fazê-lo em outros espaços. Aqui, diferentemente do fenômeno da configuração observada por Elias e Scotson (2000), os bolsistas não possuem as ferramentas para estigmatizarem ou excluírem os não bolsistas já que, no jogo, estão em nível de poder inferior. Além disso, as relações entre os dois grupos são demasiadamente estreitas em boa parte das situações - o que inviabiliza simplesmente excluir e prescindir do outro grupo.

Possibilidade alternativa para lidar com a situação seria tentar mascarar sua identidade e as diferenças intergrupos. Contudo, para a maioria dos entrevistados, especialmente em cursos de alto custo, é possível identificar o bolsista do ProUni a partir do estilo de se vestir e de se portar, que reflete mais que a mera opção de 
roupa. Reflete o estilo de vida, as escolhas do grupo dominante, seu habitus e a distinção criada entre uns e outros grupos. (Bourdieu, 2007)

Eu acho que isso muda de curso para curso, sabe? No meu era um curso muito caro e fica realmente fácil de identificar. Onde ele vive? Aonde ele costuma almoçar? Como ele se veste? Aonde ele costuma sair para beber com os amigos? Quantos amigos você tem em comum com ele? (E, 23 anos)

Corroborando o estudo apresentado por Aries e Seider (2005), a não homogeneidade do acúmulo de capital entre estudantes de diferentes origens socioeconômicas se mostra um evidente sinal de diferenciação. $\mathrm{Na}$ opinião da maioria dos estudantes, é impossível se deixar confundir entre um bolsista e um não bolsista, devido à diferença no acúmulo de capital nas mais diversas formas.

Entretanto, para os entrevistados, também era possível identificar o bolsista a partir de aspectos imateriais, dentre os quais o mais destacado era o desempenho escolar. Para eles, os bolsistas precisavam se esforçar mais, o que fazia com que o desempenho escolar fosse diferenciado em relação aos não bolsistas. Ou seja, o acúmulo de um capital escolar específico também tornava evidente a diferenciação entre bolsistas e não bolsistas. Porém, diferentemente dos demais tipos de capital, este atuava a favor do estudante bolsista.

Na minha sala tinham 60 estudantes e 10 deles eram do ProUni (pausa). Os dez melhores eram exatamente aqueles dez. Na minha opinião, o estudante do ProUni costuma ser o melhor aluno das classes. A gente precisa ser! Aquela era nossa oportunidade pra uma vida melhor. Nós não poderíamos perder aquela bolsa. A gente tinha que estudar mais do que os alunos normais. A verdade é que nós provavelmente teríamos somente sido bons estudantes de ensino médio sem esta oportunidade. Agora nós não podemos perder o que estamos recebendo. Você consegue imaginar se a gente perdesse isso? 0 que iríamos fazer depois? Quando teríamos outra oportunidade como essa? Se você parar pra pensar sobre estas questões vai entender. 0 prounista é o melhor porque aquela é a chance dele. (M, 23 Anos)

A gente não tem tanto tempo pra brincadeiras e festas como nossos colegas. Eu não estou dizendo que todos eles são 'folgados', mas eles vieram de boas escolas, né? Eles tiveram muitas oportunidades. (pausa) Aí agora eles estão tendo uma nova chance e provavelmente vão ter muitas outras durante a vida. Vão ter novas chances sempre que alguma coisa der errado. A gente não vai ter outra. A gente precisa daquilo! Muitos deles não querem estudar de verdade ou estão na faculdade só pra agradar os pais ou porque são obrigados. Uma outra grande parte deles não tem a mínima ideia do que querem pra vida e estão na faculdade somente para se divertir, ir pra festas e bares e conhecer mais gente pra sair com eles. A gente estava lá pela nossa vida. Aquela era 
nossa grande chance. A gente é diferente e é natural que a gente ande junto. A gente não tá aqui pra brincadeira." (I, 26 Anos)

Neste ponto, observamos, na construção da "fantasia coletiva" (Elias, Scotson, 2000, p. 35) dos bolsistas sobre si mesmos, o esforço de naturalizar as características positivas do grupo. Assim, em diversas frases como "precisa ser", "não poderíamos", “tinha que estudar mais", o grupo associa seu autoelogio a uma necessidade, a um imperativo sobre o qual não tem controle. Consequentemente, para eles, muito raramente o bolsista do ProUni não figurará entre os melhores estudantes dos cursos e, ainda assim, quando não forem os melhores alunos, estarão entre os mais esforçados.

Em adição, há a percepção de que precisam potencializar o gap de desempenho escolar existente entre eles e os não bolsistas como única maneira de se projetarem num mercado profissional futuro, uma vez que, em função da melhor estrutura familiar e financeira, os estudantes não bolsistas continuarão tendo maior leque de oportunidades e que o destaque no desempenho escolar é o único "trunfo" a favor dos bolsistas.

Segundo alguns dos entrevistados, o elevado desempenho chega a ponto de os bolsistas sofrerem uma espécie de "bullying inverso": sofrem perseguições por se portarem como "nerds da primeira fila".

Nós sofremos Bullying inverso. Sofremos bullying porque trabalhamos demais, perguntamos demais (pausa) Somos muito esforçados, sabe? Eles costumam dizer que somos loucos e que trabalhamos bem mais que o necessário. Talvez eles estejam certos... (pausa) Mas a gente precisa disto. A gente era o grupo dos pobres na faculdade. Nós moramos longe. A gente não tem dinheiro pra 'torrar'. A gente nunca teve a chance de viajar pelo mundo. (pausa) Então aquela era nossa oportunidade de ter estas experiências um dia. A gente precisa trabalhar muito agora pra mudar as coisas um dia. (M, 23 Anos)

Ainda que muitas vezes não tenha transparecido inicialmente, ficou nítido depois que os estudantes bolsistas costumavam se relacionar majoritariamente com outros bolsistas. Este é um ponto importante, pois alerta para a formação de seu habitus: constroem suas escolhas, montam suas estratégias, orientam suas práticas e, depois, caminham para, no cotidiano, "esquecê-las". Assim, embora consigam identificar facilmente os bolsistas, não percebem que seu grupo de amigos é, quase que totalmente, composto por outros bolsistas. Mais: quando questionados, não thes pareceu razoável que escolhiam seus relacionamentos baseados em similaridades sociais e culturais. Para a metade dos entrevistados, quando perguntados sobre a possibilidade de terem escolhidos seus companheiros 
na educação superior por proximidade social, a resposta automática foi 'não'. Entretanto, grande parte deles, após refletir sobre a pergunta, indicaram surpresa ao perceber que se relacionavam majoritariamente com bolsistas do ProUni e que nunca tinham se dado conta disto.

0 'aluno' do ProUni na faculdade (pausa) eram 6, mais ou menos, e era bem miscigenado. Tinha eu e mais uns da minha idade e com realidade parecida com a minha; e tinha uma pessoa que era mais madura, ela tinha deixado de estudar fazia muitos anos e tinha voltado. Ela era mais velha que a turma toda e era diferente. Mas os outros, a gente como tinha a mesma realidade, terminamos trocando experiência. No começo a gente não se conhecia e depois a gente começou a fazer trabalhos juntos, acho que porque a gente tinha o mesmo foco profissional e vinha de situações parecidas, não sei. Por incrível que pareça a gente se destacava como os melhores alunos. (D, 25 anos)

No curso de direito na minha universidade, eu nunca senti nada de preconceito e os bolsistas não andavam juntos. Se bem que tinha um grupinho... (pausa) São pessoas que vieram do nada, por exemplo. (pausa) Tem uma lista de dez pessoas que entraram pelo ProUni. Você olha quem são os dez; aí na época era o Orkut, criaram a comunidade da turma e as pessoas começam a se conhecer. E aí teve um grupinho que se reuniu mesmo, o pessoal do ProUni andava junto. Mas eu me destaquei, acho que me juntei com o povo do movimento estudantil e me destaquei, mas pensando bem, realmente, existia o grupo do ProUni, todos se conheciam e eu sabia quem eram. Eu não andava com eles, mas existia um grupo do ProUni. (G, 22 Anos)

A formação tanto do habitus quanto da coesão interna do grupo passa também pela depreciação do outro grupo. Como alertaram Elias e Scotson (2000), a fala elogiosa sobre o próprio grupo tende a não ser o bastante: é preciso depreciar o outro grupo, lançando sobre ele características negativas. Assim, os entrevistados tendiam a considerar que o estudante rico era alguém com inúmeras oportunidades que não dava a devida importância a nenhuma delas; que se comportava de forma pouco ativa; que não se esforçava para abraçar a oportunidade de conseguir se graduar. Neste sentido, naturaliza-se também o não bolsista, ao afirmar que, para eles, as oportunidades são cíclicas e inerentes à vida.

É sua responsabilidade! Não é fácil e provavelmente vai ser difícil e lento. Isso é tão óbvio. Eu só vou ter alguma coisa na minha vida quando acabar a faculdade. Eu sou advogada e eu não tenho família no ramo da advocacia. Eu não tive chances de fazer estágio em escritórios de parentes. Eu não tenho carro e dinheiro pra viver de estágio. Na minha área é impossível trabalhar sem ter carro ou dinheiro para táxi. É óbvio que é muito mais difícil pra gente do que pra eles, mas a gente precisa criar as oportunidades. Se você quer ser alguém, você precisa trabalhar mais e mais. Depois de uns poucos meses na faculdade eu entendi: Eu preciso crescer aonde eu posso crescer. Eu nunca vou ter as mesmas oportunidades que os meus colegas ricos, então eu preciso investir na área que pode 
mudar minha vida. Cérebro! Você precisa lutar com as armas que tem, sabe? A linha que divide quem fez e quem não fez não é somente calculada pelas suas notas, então você precisa arrumar uma maneira de crescer e usar suas notas pra isto. Você precisa de coragem mesmo, e dedicação, e devoção a achar um caminho pra seu sonho. Todo mundo tem oportunidades na vida. Às vezes é fácil, às vezes mais difícil, mas você vai ter diversas oportunidades de crescer. Você vai achar um caminho pra sua oportunidade se quiser de verdade. Talvez eu pudesse estar feliz com um simples trabalho, uma vida simples... Eu sou diferente dos outros, pois eu sei o que eu quero pra minha vida. Acredite em Deus e em você mesmo e nada é impossível. Nada. Você pode criar a chance de sua vida. (T, 25 Anos)

Ademais, percebe-se na fala dos entrevistados a ideia de que as oportunidades se tornaram reais, materializaram-se. Na opinião deles, programas como 0 ProUni intensificam, por meio da experiência, o discurso de que sucesso depende exclusivamente de trabalho árduo. Adicionalmente, transparece a ideia de que as pessoas não buscam abraçar estas oportunidades justamente quando ainda não têm dimensão exata do que objetivam na vida. Para os entrevistados, a oportunidade de acesso à educação superior é única e deve ser tratada como a grande chance de sucesso profissional - seja para o estudante bolsista, seja para o não bolsista.

[...] e fazer faculdade é o seguinte (pausa) eu acho importante a faculdade, né? É importante porque ela abre horizontes. Ela tem uma gama de possibilidades de você ingressar, depois de formado, no mercado de trabalho. É como se fosse uma garantia, sabe? É uma garantia de alguns projetos seus. [...] A faculdade é importante porque (pausa) você tem outros horizontes. Você pode galgar coisas maiores, ela dá essa perspectiva de você conseguir coisas maiores. (R, 22 Anos)

Apesar da naturalização, existem "pontos cegos" nas falas dos bolsistas, como a presença, no grupo, de indivíduos cujo desempenho escolar não é superior aos demais. A esta ocorrência eles respondem tentando manter a coesão do grupo, buscando outras características elogiosas: estes indivíduos se esforçam para compensar qualquer defasagem. Existem, contudo, outros "pontos cegos" que possuem potencial desestruturador ainda maior: bolsistas desleixados e não bolsistas esforçados e inteligentes. A estes (que não podem ser respondidos com a mesma estratégia de eleição de outras qualidades) os bolsistas respondem a partir de ideias como "excepcionalidade" e "desvio".

A gente se dedica mesmo. [...] Não vou dizer que os bolsistas eram os melhores absolutamente, pois tinham pessoas que pagavam que era muito bons alunos. Mas vou dizer, dos doze, nove eram pessoas acima. Eram alunos que se dedicavam, que nunca ficavam de recuperação, que estudavam mesmo. Que pensavam que tinham conseguido aquilo com muito esforço e não poderiam perder. Por outro lado, a maioria... sei lá, $65 \%$, 
digamos. Se dois prounistas não ligavam; nos quarenta alunos regulares, trinta estavam nem ai. "Vou estudar é de véspera mesmo, se perder ou não tanto faz mesmo." Mas havia outros que eram bons e pagavam. Tinha um que queria ser ministro do STF, era quem melhor escrevia na sala e era dos que pagavam. 0 fato é que proporcionalmente eles eram poucos: poucos desleixados do ProUni e poucos dedicados entre os que pagavam. (P, 23 Anos)

Quando refletem sobre as diferenças marcantes entre os dois grupos, os bolsistas percebem que a chance restante a eles é aumentar o poder que thes é conferido pelo desempenho na vida acadêmica de modo a, via destaque na instituição, galgar espaços, seja na vida acadêmica, seja por meio de concursos públicos, seja por meio de indicação dos professores a trabalhos na iniciativa privada.

Diante da apropriação de um capital valorizado no campo específico (no caso, o capital escolar na educação superior), bolsistas passaram a se portar enquanto sujeitos dominantes neste espaço social, ou, em outras palavras, passariam a perceber que a estratégia - ainda que pautada na aceitação da nítida diferença entre grupos - seria tentar portar-se enquanto dominante no campo. E, de maneira pouco convencional, buscar criar uma configuração na qual, nesse domínio específico da educação superior, o poder simbólico e o capital cultural não caminhem paralelamente.

\section{Considerações finais}

Não obstante a diferença inicial dê-se a partir dos padrões distintos de acúmulo de capital social, cultural e econômico, ela se expande e se alimenta para além dele, a partir da própria fala dos bolsistas e de qualidades de grupo, como preguiça, trabalho árduo, etc. Neste sentido, embora a desigualdade social e a diferença de capital sejam fundantes, seu efeito modifica-se a partir da ruptura identitária provocada pelo acesso a uma trajetória típica de outra classe, e acomoda-se a partir da ressignificação e readaptação da expansão de sua fronteira simbólica.

Com este movimento, os entrevistados demonstram perceber que não só o mundo da educação superior privada é novo para eles, mas que mesmo eles são novos naqueles ambientes - o que os leva a um pertencimento transitório, de baixa intensidade, uma vez que seu principal objetivo ali é buscar resolver o gap de capital cultural e utilizá-lo, num breve futuro, em busca de oportunidades.

Dessa maneira, com base no dito por Moon (2012), os estudantes bolsistas terminam por classificar-se como um forte e homogêneo grupo. Eles se relacionam entre si e, frequentemente, se consideram como mais "merecedores" da educação superior que os estudantes não bolsistas. 
Os bolsistas tendem a organizar seu pertencimento a partir do fortalecimento do novo grupo, que quer fazer-se distinto não por características econômicas, étnicas, raciais e/ou de gênero, mas por uma reinterpretação bastante particular da meritocracia, segundo a qual eles merecem mais do que os outros por, devido ao seu esforço e inteligência, conseguirem modificar sua posição inicial e tornaremse mais intelectualmente capazes que seus colegas não bolsistas.

Ao longo do seu processo de adaptação a um novo ambiente, os bolsistas demarcam sua identidade de grupo a partir da criação de limites entre eles e os estudantes não bolsistas, elegendo qualidades como esforço, inteligência, foco, dentre outras, que convergem para a ideia de merecimento.

Agindo assim, não só os bolsistas modificam sua posição inicial, como criam um novo tipo de pertencimento, ligado ao seu direito legítimo como protagonistas deste novo espaço. Dessa forma, eles buscam projetar um novo tipo de poder que lhes garanta a posição de estabelecidos, acentuando as dimensões meritocráticas já existentes no espaço da educação superior.

Pelo exposto, parece que estamos diante de um novo tipo de grupo de estudantes - o que enseja a ampliação das ferramentas e metodologias atuais de pesquisa. Dessa maneira, enquanto a literatura específica trata da relação direta entre acúmulo de capital cultural e autocategorização de grupo dominante na educação superior, o caso do bolsista do ProUni mostra uma configuração em que se torna rarefeita a correlação entre origem socioeconômica baixa e dominação do campo.

Ao assumir sua diferença e classificar-se como melhor, o bolsista coloca em segundo plano as distinções de capital econômico, social e cultural, evidencia o sucesso escolar, coloca em cheque a manutenção das trajetórias sociais de seus colegas não bolsistas e abre possibilidades para tornar-se um novo tipo de sujeito.

\section{Referências}

ALMEIDA, Ana Maria; PEROSA, Graziela; ROCHA, Maria Silvia; TOMIZAKI, Kimi Aparecida. Experiências educativas e construção de fronteiras sociais. Revista Luso-Brasileira Sociologia da Educação, Rio de janeiro, v.1, pp. 10-39, 2010.

ALMEIDA, Wilson Mesquita. Ampliação do Acesso ao Ensino Superior Privado Lucrativo Brasileiro: um estudo sociológico com bolsistas do ProUni na cidade de São Paulo. 294 f. Tese (Doutorado em Sociologia) - Faculdade de Filosofia, Letras e Ciências Humanas, Universidade de São Paulo, 2012.

ALON, Sigal; TIENDA, Marta. Diversity, Opportunity, and the Shifting Meritocracy in Higher Education. American Sociological Review, Thousand Oaks, v.72, n. 4, pp. 487-511, 2007.

ARIES, Elizabeth; SEIDER, Maynard. The Interactive Relationship Between Class 
Identity and the College Experience: The Case of Lower Income Students. Qualitative Sociology. v. 28, n. 4, pp. 419-443, 2005.

AYALON, Hanna; GRODSKY, Eric; GAMORAN, Adam; YOGEV, Abraham. Diversification and inequality in higher education: A comparison of Israel and the United States. Sociology of Education, New York, v. 81, n. 3, pp. 211-241, 2008.

BERGERSON, Amy. Exploring the impact of social class on adjustment to college: Anna's story. International Journal of Qualitative Studies in Education, v. 20, n. 1, pp. 99-119, 2007.

BERNARD, Russell. Research methods in anthropology: qualitative and quantitative approaches. Lanham: Altamira Press, e. 4, 2006.

BOURDIEU, Pierre. Condição de Classe e posição de classe. In: MICELI, Sergio (Org.), A economia das trocas simbólicas, pp. 99-181. São Paulo: Perspectiva, 1974. . Les trois états du capital culturel. Actes de la recherche en sciences sociales, Paris, n. 30, pp. 3-6, 1979.

. 0 poder simbólico. Lisboa: Difusão Editorial, 1989. A miséria do Mundo. Petrópolis: Vozes, 7 ed., 2008.

A Escola Conservadora: as desigualdades frente à escola e a cultura. In: NOGUEIRA, Maria Alice; CATANI, Afrânio Mendes. (Org.) Escritos de Educação. pp.39-64. Petrópolis: Vozes, 1998a..

. Futuro de classe e causalidade do provável. In: NOGUEIRA, M.A.; CATANI, A. (Org.) Escritos de Educação. pp.81-126. Petrópolis: Vozes, 1998b..

.Esboço de uma teoria da prática. Precedido de três estudos de etnologia Kabila. Oeiras: Celta, 2002

. A Distinção: critica social do julgamento. São Paulo: Edusp; Porto Alegre, RS: Zouk, 2007.

CARVALHO, Cristina. O PROUNI no governo Lula e o jogo político em torno do acesso ao ensino superior. Educação e Sociedade, Campinas, v. 27, pp. 633-1074, 2006.

CASTELLS, Manuel. 0 poder da identidade. São Paulo: Paz e Terra, 1999.

CATANI, Afrânio; GILIOLI, Renato. 0 ProUni na encruzilhada: entre a cidadania e a privatização. Linhas Críticas, Brasília, v. 11, n. 20, pp. 55-68, 2005.

DRAGAN, Irina-Maria; ISAIC-MANIU, Alexandru. Snowball Sampling Completion. Journal of Studies in Social Sciences, Sydney, v. 5, n. 2, pp. 160-177, 2013.

DUBAR, Claude. Trajetórias sociais e formas identitárias: alguns esclarecimentos conceituais e metodológicos. Educ. Soc., Campinas, v. 19, n. 62, pp. 1-9, Abr. 1998. . Entre crise global e crises ordinárias: a crise das identidades. PLURAL, São Paulo, v.18.1, pp.175-184, 2011.

ELIAS, Norbert; SCOTSON, John. Os estabelecidos e os outsiders. Rio de Janeiro: Zahar, 2000. 
FRANCIS, Andrew; TANNURI-PIANTO, Maria. The Redistributive Equity of Affirmative Action: Exploring the Role of Race, Socioeconomic Status, and Gender in College Admissions. Economics of Education Review, Amsterdam, v. 31, pp. 45$55,2012$.

GOLDRICK-RAB, Sara. Following Their Every Move: An Investigation of SocialClass Differences in College Pathways. Sociology of Education, New York, v. 79, n. 1, pp.61-79, 2006.

GOODMAN, Leo. Snowball Sampling. Annals of Mathematical Statistics, Beachwood, v. 32, pp. 148-170, 1961.

GROSS, Neil; CHENG, Catherine. Explaining professors' politics: Is it a matter of self-selection?. In STULBERG, Lisa; WEINBERG, Sharon. (org.), Diversity in American higher education: Toward a more comprehensive approach, pp. 178-194. New York: Routledge, 2011.

HALL, Stuart. A identidade cultural da pós-modernidade. Rio de Janeiro: DP\&A, 2005.

INEP.SUPERIOR. Ministério da Educação. Instituto Nacional de Estudos e Pesquisas Educacionais. Microdados do Censo Escolar da Educação Superior 2012. Brasília: MEC/INEP, 2013.

LACLAU, Ernesto. Universalism, Particularism, and the Question of Identity. October, V. 61, The Identity in Question, pp. 83-90, Summer, 1992.

LAMONT, Michèle; FOURNIER, Marcel. Cultivating Differences: Symbolic Boundaries and the Making of Inequality. University of Chicago Press: Chicago, 1992.

LAMONT, Michèle; SILVA, Graziella. Complementary rather than contradictory: diversity and excellence in peer review and admissions in American higher education. 21st Century Society, v. 4, n. 1, pp. 1-15, 2009.

LAMONT, Michèle; LAREAU; Annette. Cultural Capital: Allusions, Gaps and Glissandos in Recent Theoretical Developments. Sociological Theory, Washington, v. 6, n.2, pp. 153-68, 1988.

LAMONT, Michèle; MOLNÁR, Virág. The Study of Boundaries Across the Social Sciences. Annual Review of Sociology. V. 28, pp. 167-195, 2002.

LAREAU, Annette. Social class differences in family-school relationships. The importance of cultural capital. Sociology of Education, New York, v. 60, pp. 73-85, 1987.

LEHMANN, Wolfgang. "I just didn't feel like I fit in": The role of habitus in university dropout decisions. Canadian Journal of Higher Education. v. 37, n. 2, pp. 89-110, 2007.

LOPES, Claudia; RODRIGUES, Laura; SICHIERI, Rosely. The lack of selection bias in a snowball sampled case-control study on drug abuse. International Journal of Epidemiology, Oxford, v. 25, n.6, pp. 1267-1270, 1996. 
MCCOWAN, Tristan. Expansion without equity: An analysis of current policy on access to higher education in Brazil. Higher Education, London, v. 53, pp. 579-598, 2007.

MELLO NETO, Ruy de Deus e. PROUNI: Dimensão nacional e perfil dos estudantes em Pernambuco. 219 f. Dissertação (Mestrado em Educação) - Faculdade de Educação, Universidade Federal de Pernambuco, 2011.

MELLO NETO, Ruy de Deus e. Entre melhores e piores: caso dos bolsistas do ProUni em Pernambuco. In SIMÕES, José Luís (org.). Pesquisas em teoria e história da educação. v.2, Recife: Ed. Universitária, 2014.

MODO0D, Tariq. Capitals, Ethnic Identity and Educational Qualifications. Cultural Trends, v. 13, n. 50, pp. 25-45, pp. 87-105, 2004.

MOON, Dawne. Who Am I and Who Are We? Conflicting Narratives of Collective Selfhood in Stigmatized Groups. American Journal of Sociology. v. 117, n. 5, pp. 1336-1379, 2012.

OLIVEN, Arabela. Inclusion Policies in the Brazilian System of Higher Education: the public and the private sector. Journal of US-China Public Administration, MeiZhong Gonggong Guanli, v. 9, pp. 1302-1310, 2012.

OSTROVE, Joan. Belonging and wanting: Meanings of social class background for women's constructions of their college experiences. Journal of Social Issues, Hoboken, v. 59, n.4, pp. 771-784, 2003.

OSTROVE, Joan; LONG, Susan. Social class and belonging: Implications for college adjustment. Review of Higher Education, Baltimore, v. 30, n. 4, pp. 363-389, 2007.

SANTOS, Boaventura de Sousa. Os processos de globalização. In___ (org.). Globalização: fatalidade ou utopia? Porto: Edições Afrontamento, pp. 11-99. 2001. SISPROUNI. Sistema Informatizado do PROUNI. Bolsas disponibilizadas por ano. Disponível em: <http://prouniportal.mec.gov.br/images/arquivos/pdf/ Representacoes_graficas/bolsas_ofertadas_ano.pdf> Acesso em: 22 jan. 2014.

SMALL, Mario Luis; HARDING, David; LAMONT, Michèle. Reconsidering Culture and Poverty. The ANNALS of the American Academy of Political and Social Science, v. 629, pp. 6-27, 2010.

SCHWARTZMAN, Luisa; SILVA, Graziella. Unexpected Narratives from Multicultural Policies: Translations of Affirmative Action in Brazil. Latin American and Caribbean Ethnic Studies, San Diego, v. 7, n.1, pp. 31-48, 2012.

TAVOLARO, Lília. Affirmative Action in Contemporary Brazil: Two Institutional Discourses on Race. International Journal of Politics, Culture and Society, New York, v. 19, pp. 145-160, 2008.

TRAVERS, Jeffrey; MILGRAM, Stanley. An Experimental Study of the Small World Problem. Sociometry, Washington, v.32, n.4, pp. 425-443, 1969.

WARIKO0, Natasha; CARTER, Prudence. Cultural Explanations for Racial and 
Ethnic Stratification in Academic Achievement: A Call for a New and Improved Theory. Review of Educational Research, New York, v. 79, n. 1, pp. 266-394, 2009.

ZIMDARS, Anna. Fairness and undergraduate admission: A qualitative exploration of admissions choices at the University of Oxford. Oxford Review of Education, Oxford, v. 38, n. 3, pp. 207-323, 2010.

Recebido em setembro de 2014

Aprovado em outubro de 2014

Ruy de Deus e Mello Neto é doutorando em Educação pela Universidade de São Paulo (USP), na linha de pesquisa Estado, Sociedade e Educação. Realizou estágio de pesquisa na Harvard Graduate School of Education (Cambridge, MA/EUA). E-mail: ruydedeus@usp.br

Hugo Augusto Vasconcelo Medeiros é doutorando em Educação pela Universidade Federal de Pernambuco (UFPE). E-mail: hugoavmedeiros@agmail.com

Afrânio Mendes Catani é doutor em Sociologia pela Universidade de São Paulo (USP). Livre-Docente no período 2006-2009, atualmente é professor titular na Faculdade de Educação da Universidade de São Paulo e professor no Programa de Pós-Graduação em Integração da América Latina (PROLAM) - USP. E-mail: amcatanidusp.br 